\title{
Las mujeres como objeto de estudio en la revista Archivos de criminología aplicadas a las ciencias afines en Argentina (1902- 1913)
}

\section{The women as object of study in the Archivos de criminología aplicadas a las ciencias afines in Argentina (1902-1913)}

\author{
Ana Elisa Ostrovsky \\ Universidad Nacional de Mar del Plata \\ Consejo Nacional de Investigaciones Científicas y Técnicas \\ Viviana Alfonso \\ Universidad Nacional de Mar del Plata \\ Argentina
}

\begin{abstract}
Resumen
El presente artículo tiene como finalidad analizar a las mujeres como objeto de estudio en la Revista Archivos de criminología aplicadas a las ciencias afines en la Argentina en el periodo comprendido entre 1902 y 1913. Nos detendremos particularmente a contemplar las características de las mujeres estudiadas en sus páginas, diferenciando aquellos casos que fueron judicializados de los que no fueron objeto de intervención penal. En dicho recorte mostraremos cómo la consideración jurídica y científica de los mismos estaba imbuida en los valores de género de la época sobre los roles esperables para las mujeres.
\end{abstract}

Palabras clave: criminología; mujeres; Argentina; siglo XX; valores

\begin{abstract}
The present article aims to analyze women as an object of study in the Revista Archivos de criminologia aplicadas a las ciencias afines in Argentina in the period that goes between 1902 and 1913. We will particularly focus on considering the characteristics of women studied in its pages, differentiating the prosecuted cases from those that were not part of a criminal intervention. In this cutout we will show how the legal and scientific consideration of them was imbued in the gender values of the time regarding the expected roles for women.
\end{abstract}

Keywords: criminology; women; Argentina; twentieth century; values

\section{Introducción}

El proceso de modernización y expansión económica de la Argentina de finales de siglo XIX y comienzos del Siglo XX, que supuso la secularización de sus instituciones y la consolidación del modelo económico agroexportador, tuvo como contrapartida en las elites gobernantes la preocupación por la "cuestión social" como un concepto que englobaba problemas derivados de la inmigración masiva y la consecuente elevación de las tasas poblacionales (Suriano, 2004). La postal decimonónica de la capital del país, la potente ciudad de Buenos Aires con su puerto mirando al mundo, se modificó 
ostensiblemente requiriendo estrategias en el plano urbano y sanitario. El ideario que operó las primeras transformaciones, reformista y liberal, albergó tanto a corrientes católicas como a desarrollos socialistas apuntando a un reordenamiento social que iba desde el plano moral hasta los cambios institucionales que desembocarían en una reforma electoral en 1912. (Zimmermann, 1992). Los liberales reformistas de aquella época, integrantes de una elite política e intelectual, consideraban que la solución a la cuestión social radicaba en una regulación científica de los conflictos sociales. Producto de tal movimiento fue la creación de instituciones estatales destinadas al estudio y tratamiento de la nueva problemática (Asistencia Pública, Instituto de Criminología de la Penitenciaría Nacional, etc.), así como la creación de novedosos campos profesionales y cursos universitarios (Sociología, Criminología) (Lancelotti, 1912). El discurso positivista, adaptado a las necesidades locales, halló protagonismo en el centro de esta escena. Sus postulados lograban conciliar bajo un halo de cientificidad, un profeso liberalismo con la tradición conservadora del gobierno vigente (Candioti, 2002). Los problemas que hasta entonces habían encontrado solución por parte de un estado de política policial represiva, serían entonces objeto de una nueva mirada: el reformismo. Las soluciones provendrían desde lo "científico" y su fundamentación desde el estudio empírico del problema (Talak \& Miranda, 2010).

En dicho marco la criminología se esgrimió como un novedoso saber científico para el problema de la delincuencia. Entre 1899 y 1914 las estadísticas policiales daban cuenta del aumento de delitos contra las personas y la propiedad, y las estadísticas penitenciarias arrojaban un aumento en la población carcelaria, que "casualmente", era extranjera, y que también era predominante en los hospicios psiquiátricos (Di Corleto, 2010; Sozzo, 2016; Vezzetti,1983) A partir de la influencia del positivismo, el código penal vigente denominado código Tejedor, fue criticado por centrarse desde la perspectiva clásica más en el acto que en el sujeto y se introdujeron nuevas concepciones en la Ley de Residencia No 4144 de 1902, la Ley de Defensa Social N07029 de 1910 y la política de deportación en 1903. (Dalla Corte Caballero, 1996a; Salvatore, 2005).

Respecto al género, las estadísticas arrojaban una proporción de delitos menor en las mujeres que en los varones. El número de delitos cometidos por las mujeres además era inversamente proporcional a su gravedad (Dalla Corte Caballero, 1996b). Los delitos como los encubrimientos, envenenamientos, abortos, infanticidios e incendios eran considerados propios de las mujeres por requerir éstos menos fuerza física y complejidad intelectual (Banerjee, Islam \& Khatun, 2015; Sánchez, 2004). La visión de la Escuela Italiana de Cesare Lombroso señalaba anomalías en el desarrollo del encéfalo y un tipo de criminalidad relacionada con las funciones femeninas: "La 
criminalidad de la mujer es específica, limitada a lo que es precisamente su función social: al amor y a la maternidad" (Lombroso, 1899, p. 201).

En materia jurídica, siguiendo al Código Civil de 1871, las mujeres en Argentina no podían estudiar, trabajar o comerciar sin el permiso del padre, hermano o esposo, ni tampoco podían disponer de sus bienes, pero sí eran plenamente responsables por sus delitos. La legislación penal de 1886 admitía igual responsabilidad para las mujeres y los varones aunque éstas eran eximidas de la pena de muerte, al igual que los menores de edad y los mayores de setenta años.

La revista, cuyo nombre completo era Archivos de Psiquiatría y Criminología aplicadas a las Ciencias Afines. Medicina Legal, Sociología, Derecho, Psicología y Pedagogía fue fundada por el médico Francisco De Veyga y tuvo como antecedente la revista Criminalogía Moderna, proyecto finisecular del abogado anarquista italiano Pietro Gori, quien realizó actividades científicas y políticas en Argentina desde 1898 hasta 1902 (Albornoz Crespo, 2016).Su denominación se inspiró estratégicamente en el prestigioso Archivio di psichiatria, antropología criminale e scienze penali per servire allo studio dell'uomo alienato e delinquente del citado representante de la escuela italiana Cesare Lombroso. Dirigida desde 1902 por José Ingenieros ${ }^{1}$, y de edición bimestral, la publicación tuvo un alcance que desbordó las fronteras del país, constituyendo una referencia para la criminología latinoamericana y manteniendo un diálogo con los principales referentes de la disciplina en Europa (Rossi, 2007). Desde 1907 fue además el órgano del Instituto de Criminología, lugar desde el cual Ingenieros continuó su mirada psicopatológica sobre el examen del delincuente (Ingeneiros, 1902, 1905). El último número de la revista fechado en diciembre de 1913, dejó una estela de doce tomos de publicación ininterrumpida. Su alcance geográfico, relevancia y continuidad a través de diez años la ubica como a una fuente jerarquizada para pensar cómo era el tratamiento de los delitos relacionados con las mujeres en aquellos años.

Con respecto a su ubicación geográfica, es interesante mencionar que en los casos relevados en la revista, pese a que se observa alguna mención a la inmigración, la especificidad de lo local no aparece, incluso cuando muchos se enmarcaban como problemas derivados de la "cuestión social". Estéticamente la publicidad y la moderna fotografía incluida en sus páginas replicaba los cánones europeos (Ciancio \& Gabriele, 2012). Un ejemplo de lo antedicho son las imágenes de parálisis histéricas inspiradas en el archivo fotográfico de la clínica francesa Salpêtrière (Mailhe, 2014).

\footnotetext{
${ }^{1}$ José Ingenieros (1877-1925) filósofo y médico polifacético de origen italiano radicado tempranamente en la Argentina. En el campo de la psicología representó a la psicología naturalista de comienzos de siglo XX como profesor de la cátedra Psicología Experimental en la Facultad de Filosofía y Letras de la Universidad de Buenos Aires en 1908 y como miembro fundador de la Sociedad de Psicología de Buenos Aires.
} 


\section{Metodología}

Para analizar los casos que tuvieron a mujeres como protagonistas en la revista, realizamos un abordaje de la misma que tomó las fases tradicionalmente demarcadas por la metodología general de la historia (Klappenbach, 2014; Tkocz \& Holguín, 2018; Topolsky, 1985). En un primer momento, de carácter heurístico, nos abocamos a la detección y tipificación de la fuente, la colección completa de la revista compuesta por doce tomos y una fase de crítica externa donde se realizó una primera clasificación y fichado. Respecto a las características de la fuente, cabe señalar que la revista Archivos tenía aproximadamente sesenta páginas. Desde 1902 hasta 1913 se publicaron 12 tomos (del número I al XII). Su estructura contaba con tres grandes secciones: Artículos, Variedades y Análisis de libros y revistas. Se publicaron en total 592 artículos. El primer número contó con 77 trabajos, siendo el más numeroso. En 1903 se publicaron 69 artículos, en 190440 trabajos, en 190548 aportes, en el año 1906 45, 52 artículos en 1907, 35 en 1908, 47 en 1909, 44 aportes en 1910, 49 en 1912 y 57 en 1913. Las prácticas investigativas estuvieron dirigidas a ubicar la fuente (la colección completa de la revista), generar dispositivos adecuados para su mejor sistematización (digitalización de parte del material) y establecer parámetros clasificatorios de las misma (algunos básicos como autor, año y temática, y otros relacionados con la presencia o ausencia de mujeres como protagonistas de los artículos y el tipo de delito relatado. Una vez sistematizado el material, se procedió a la crítica interna o fase hermenéutica donde se interpretó la fuente de acuerdo a los parámetros que guiaron nuestra indagación. Los artículos relevados provenían tanto de la pluma de los criminólogos argentinos como de los trabajos de estudiosos de la región u otras latitudes. A los efectos de nuestro trabajo se tomaron solo los artículos que tuvieron a mujeres como protagonistas y que se desarrollaran dentro del ámbito nacional. El total de la muestra quedó conformado por 17 artículos. Dentro de los mismos se empleó como criterio deslindar los casos judicializados (5 casos) donde las mujeres objeto de análisis tuvieron algún tipo de sentencia o proceso judicial, de aquellos trabajos que presentaban relatos de casos, experiencias, etc. pero que muestran a mujeres que no tuvieron derrotero alguno por el sistema penal. Cabe destacar que no se registró el aporte de ninguna mujer en calidad de autora.

\section{Las aristas de la cuestión femenina}

Los roles femeninos en el periodo estudiado se encuadraban dentro del binomio conservador que ubicaba a la mujer en el espacio privado y al varón en el espacio 
público. Como ha señalado Dora Barrancos, si bien el período que va desde 1880 a 1930 fue fecundo en transformaciones materiales y técnicas, y abrió la conquista laica a diversos espacios otrora potestad de la iglesia católica, la cultura liberal imperante fue incompleta respecto de los derechos individuales personalísimos, perviviendo sensibilidades conservadoras y modelos pasivizantes de lo femenino (Barrancos, 2014). Dichas concepciones están presentes en los tópicos elegidos en la revista. Por ejemplo, en los casos presentados que no tuvieron su derrotero por la justicia penal pero sin embargo fueron objeto de análisis criminológico, podemos delimitar dos grandes tipos de temas relacionados con la intimidad femenina en su faz pública y privada. Por una parte se presentan aquellos actos cometidos por mujeres que atentaban contra la moral y las buenas costumbres de la época o las tenían por objeto de intervención, y por el otro aquellos ilícitos íntimamente relacionados con el histericismo y la sexualidad.

Dentro de las primeras encontramos problemáticas de índole sanitaria como la prostitución y la denominada trata de blancas. Tal es el caso del artículo de 1904 escrito por Belisario Montero, quien era cónsul argentino en Bélgica y analizaba el tema como comercio internacional que involucraba a la nación. Descontando la vulnerabilidad de las jóvenes inmigrantes, e incluso las redes existentes para cooptar a las mismas (Trochón, 2006), el autor consideraba que las mujeres argentinas eran difíciles de reclutar para el comercio sexual, lo que llevaba a las casas de tolerancia a buscar prostitutas extranjeras. Montero creía que la moralidad de un estado debía cancelar los establecimientos de prostitución por dañinos y peligrosos. Sin embargo, a su parecer, esto dependía de un cambio en las concepciones sociales que entendían a dichos establecimientos como un mal necesario. La solución inmediata que proponía era que las propias compañías de navegación contribuyeran a la represión de dicho comercio, señalando pasajeros sospechosos y denunciándolos ante los consulados correspondientes (Montero, 1903).

El tema de la prostitución tuvo especial importancia ya que se discutía qué tipo de reglamentación debía adoptar el país desde una óptica sanitaria, a la par que desde los medios de comunicación se exhibían abiertamente productos para tratar problemas venéreos, mostrando masivamente los peligros de la promiscuidad (Biernat \& Simonetto, 2017). Esto involucraba un modelo de ideología respecto de qué era lo que la sociedad de por entonces permitía, toleraba y requería (Dovio, 2013). Al respecto, en los Archivos hallamos diferentes matices. Desde una óptica reglamentarista Enrique Prins, Secretario de la Asistencia Pública, sostenía que la legislación no cambiaría en nada la prostitución, más bien había que reglamentarla ya que no se podía ir contra el orden natural de los acontecimientos. La consideraba como una perversión precoz, y se preguntaba si en realidad las leyes escritas podían 
influir en algo respecto de su disminución. La ley tendría sólo influencia operando sobre la verdadera amenaza: la prostitución clandestina. El único peligro moral que creía existía, era la proximidad de las casas de tolerancia respecto de las escuelas, por la curiosidad propia de los niños (Prins, 1903). En la vereda legalista Enrique Revilla, director de la Asistencia Pública afirmaba que reglamentar la actividad no sólo llevaría a proteger la salud y el orden público, sino que apuntaría a que quienes la ejerciesen pudieran "ascender" de nivel; dejar de ser rameras para pasar a ser "cocottes" (Revilla, 1903). Para esto desalentaba la creación de zonas donde se concentrasen casas de prostitución a gran escala y proponía el patentamiento de la prostituta, con su correspondiente libreta donde debían figurar los periódicos controles sanitarios y una foto identificadora. A su vez, las casas de tolerancia no deberían situarse más que una por cuadra y a dos cuadras libres de iglesias, teatros y colegios. No podrían prostituirse más de tres mujeres por casa y tales sitios serían considerados como inquilinatos. Continuando con la prostitución femenina, Francisco Sicardi, profesor de la Facultad de Medicina de Buenos Aires, escribía acerca de las cárceles, la vida criminal y las mujeres que allí se encontraban por prostitución:

Se imaginará, que alguna vez en las horas aburridas, ellas pueden pensar en una vida más sana, que quieran vivir una semana siquiera en el sol puro, en la divina consagración de una virtud cualquiera, que sean capaces de comparar sus turbulencias enfermizas con la robusta marca de la mujer honesta. No es así. Ellas no saben sino aquello y no podrán sentir esas nostalgias (Sicardi, 1903, p. 15).

Sicardi plantea que si tales mujeres recuperasen la libertad, diseminarían por la ciudad gérmenes mortales y su "piscología" dejaría un reguero malsano que corrompería inocencias. Un grupo de mujeres que habrían nacido de tal forma nunca podrían estar contentas en un hogar bien constituido y cuidando los hijos (Narvalaz \& Miranda, 2009). Así, hace referencia a las mismas escribiendo: "La inquieta piensa en el placer acre y violento que hace estremecer sus carnes de elegante delincuente, en la fuga hacia las posadas oscuras" (Sicardi, 1903, p. 17). Desde una concepción de evolucionista y con elementos de la teoría de la degeneración hereditaria de A. Morel ${ }^{2}$, el autor sostenía la inevitabilidad del destino trágico de estas mujeres en una partida ancestral que ya había sido jugada desde la biología.

Con sus diferentes ángulos y valoraciones, las tres posturas concebían la prostitución como a un mal necesario e inevitable y se centraban en la figura de la

\footnotetext{
${ }^{2}$ Nos referimos al médico francés Auguste Morel quien con su Tratado de Degeneración de la Especie Humana, publicado en 1857 reformuló las ideas psiquiátricas de su época ubicando en la herencia del individuo el eje y el grado de su potencial patógeno. La idea evolucionista de degeneración se convirtió en un programa de investigación que desbordó el hospicio convocando a médicos, higienistas y juristas. La misma posibilitó que cuadros como el exhibicionismo, el alcoholismo y también la prostitución se explicasen por herencias deficientes y taras. Véase Caponi (2009).
} 
prostituta, ya sea desde su salud física como desde su posible potencial degenerativo. La figura del varón prostituyente, consumidor de dichos servicios, quedaba naturalizada y la salvaguarda de la moralidad pública se sostenía en el establecimiento de las distancias y las prevenciones necesarias.

Dentro de las causas ligadas a la sexualidad femenina encontramos el uranismo (la homosexualidad femenina) y los delitos cometidos en trance histérico o en ocasión del periodo menstrual. Víctor Mercante, reconocido pedagogo y psicólogo experimental interesado en diversas aristas de la cuestión femenina (Ostrovsky, 2011) escribió en la cuarta edición de la revista tomando como foco a los internados de señoritas de Buenos Aires. Allí estudio dos prácticas, el fetichismo y el uranismo. A su parecer, las mujeres eran conducidas al fetiche por poseer una imaginación más vívida como consecuencia de la vida retraída. La búsqueda del adorno, naturalmente destinada a captar la atención de los hombres, podría exacerbarse en la obsesión e incluso desencadenar el hurto. Como la coqueta sociedad de Buenos Aires, según el pedagogo, propendía a tentaciones permanentes como las vidrieras, una posible solución eran los internados, puesto que según Mercante 'la mujer es hija del rigor" (Mercante, 1905, p. 23). Ahora bien, allí parecía que lejos de "curarse" dicho mal se epidemizaba. En condiciones de encierro a falta de vidrieras aparecía el empleo exacerbado de amuletos y relicarios. Más grave aún era el uranismo, como entonces era llamada la homosexualidad femenina, mal a combatir con educación, vigilancia de la internada, estudio psicomoral y práctica de actividades al aire libre. Esto debía acompañarse con la prohibición del beso, el ir del brazo y el convivir dualmente (Mercante, 1905). Así para el autor, la homosexualidad femenina, acaso menos tematizada que la masculina, se inscribía entre los bordes del delito y la enfermedad.

Otra de las causas que agravaría el mencionado fetichismo era la histeria, la cual aparecía en un artículo del abogado Francisco Netri. Dicha entidad según el autor profundizaría la natural 'fascinación que en ellas provocan los encajes y "niñerías" (Netri, 1902, p. 156). El status de la histeria en los estudios psiquiátricos argentinos albergaba toda la polisemia y la carga mística que el concepto generaba en otras latitudes. Por una parte, como se observa en la obra Los accidentes histéricos y las sugestiones terapéuticas de José Ingenieros, prevalecía una concepción fisioneurológica de la misma, alejada de ideas genitales y místicas. Pero por otro lado, si nos detenemos en el análisis de los historiales clínicos, observamos cómo las mujeres, con sus ciclos, su sexualidad y sus misterios aparecían coloreando la especificidad de cada uno de los cuadros presentados, que evocaban indefectiblemente a la sexualidad (Ingenieros, 1904). Volviendo al mencionado artículo, ello se observa en las referencias de Netri, quien citando a Legrand du Saulle, comentaba que habiendo estudiado 80 ladronas, 41 eran histéricas de diferente grado 
y de éstas 35 se encontraban en la época de la menstruación. Los ritmos femeninos, misteriosos y cíclicos como la luna, eran para estos autores oscuros resortes del delito.

Por tanto no debe causar sorpresa si el lujo de la exposición de un comerciante, el fausto que brilla a los ojos del visitador, que son por cierto una excitación poderosa al delito, llegan a serlo de especial manera en las histéricas, y aún más en las menstruantes, que tienen una resistencia insuficiente al impulso delictuoso" (Netri, 1902, p. 157).

En efecto, la menstruación, el embarazo y el parto se asomaban en el horizonte del transgredir femenino. La mujer, que en la sociedad estaba anclada a su rol reproductivo, aparece delinquiendo también conforme a las aristas de ese rol (Narvalaz \& Jardón, 2010). Es interesante notar que la falta de determinación respecto de la entidad de cualquier trastorno hace que consecuentemente, al no tener sus límites definidos, su etiología descrita y sus síntomas identificados, sean pasibles de caer bajo categorizaciones de contornos difusos:

La psicosis menstrual suele ser episódica, de origen reflejo, produciéndose en mujeres taradas por fuerte herencia neuropática o afectadas por alguna de las neurosis, especialmente la histeria y la neurastenia. Como factores ocasionales de primordial importancia contribuyen la miseria fisiológica, los accidentes dismenorreicos, el surménage, etc. No posee caracteres clínicos que le pertenezcan de manera exclusiva, reviste la forma de síndromes maníacos, melancólicos, de confusión mental, erotismo, misticismo o tendencias impulsivas razonantes o parciales (cleptomanía, dipsomanía, suicidio, etc.), su evolución suele ser episódica o intermitente, de pocos días o semanas de duración (Cantón \& Ingegneros, 1903, p. 550).

De esta forma, la psicosis menstrual podía serlo todo y nada, un paragua rotulatorio aplicable a cualquier conducta femenina socialmente poco valorada. El estado de puerperio, también motivó análisis psiquiátricos con implicancias criminológicas. Pedro Oro, médico del Hospital Nacional de Alienadas, expuso en 1906 la fisonomía propia de la psicosis puerperal. El especialista planteaba relaciones entre las alteraciones patológicas del organismo y los estados mórbidos de la inteligencia. Aducía que desde el punto de vista psicológico la locura puerperal no se presentaba de manera uniforme, sino bajo formas variadas y diversas. Particularmente existían dos formas de delirio: la manía y la melancolía, siendo esta última la que generalmente aparecía en la observación clínica. Escribía el autor que una de las causas de los desequilibrios durante la etapa puerperal era la gran toxicidad presente en la sangre de las madres, la cual era equiparada a la sangre menstrual sumada a la degeneración mental hereditaria. Lo curioso desde los criterios psicopatológicos era incluir en el estudio de la denominada tara hereditaria causas predisponentes como 
las relativas al carácter moral, antiguos sufrimientos experimentados y desgracias económicas (Oro, 1906). Nuevamente observamos un cuadro psicopatológico que puede ser apagado o exaltado, hereditario o fruto de la mala fortuna, resultado de la sangre tóxica o la moral, pero que tiene como común denominador a una mujer que recientemente dio a luz y se comporta de una forma socialmente disruptiva con la buena maternidad.

En otro artículo publicado en 1910, Bernardo Etchepare, médico del Manicomio Nacional, relataba la historia de una muchacha francesa que voluntariamente se presentó para su internación a causa de su adicción a la morfina. El título del escrito es "Desequilibrio mental, morfinomanía e histerismo". Es notable cómo desde el inicio del relato se categorizan ciertos elementos que no eran valiosos para la sociedad del momento. El escrito alude a una niña que fue abandonada por su madre, producto de una relación extramatrimonial, por lo que su padre se hizo cargo de ella. El mismo muere cuando la niña tenía dos años, recalcándose que era excesivamente aficionado a las mujeres y neurópata. De esto no se tenían más datos que los dichos de la paciente. $\mathrm{Y}$ al ser su madre desconocida escribe el autor "por ese mismo hecho deja sospechar su anormalidad" (Etchepare, 1910, p. 723). Una madre que no pudiendo llevar consigo a su hija nacida fuera del matrimonio era para la época indefectiblemente una anormal. Consagra la historia de una infancia que atraviesa solitaria y sin cariño por parte de la mujer de su padre, refiriendo que la tristeza la asolaba permanentemente. A la edad de nueve años fue abusada por el padre de la madre putativa; esto se relata de la siguiente manera: "Depravada por un alienado erótico, fija en su cerebro, que no hay duda estaba preparado para ello, la imagen del placer homosexual, de la urania, y hace de esa aberración un verdadero culto." (Etchepare, 1910, p. 723).

En palabras de Etchepare, el pederasta la deprava efectuando en ella succión clitorídea. A los catorce huyó del hogar y su derrotero se inicia con un amante del cual queda embarazada y concluye en aborto. Luego baila en Moulin Rouge llegando a ser una artista reconocida. Más tarde es presa de todo tipo de toxicomanías como morfina, hachís, éter, atropina, etc. Numerosos intentos de suicidio que por circunstancias externas se vieron frustrados registraba en su historial. Se había internado voluntariamente en París a fin de tratar su adicción pero todo sin éxito. Su llegada a la Argentina se había producido en el año 1905. Recalca el relato que sólo conseguía placer sexual con otras mujeres y concluye Etchepare que la paciente era un caso de hermafrodismo sexual. El especialista relata que la paciente solicitaba dejar el Manicomio, pero éste se pregunta con qué fin, ya que él mismo consideraba que la muchacha representaba nada más que "un judío errante de su propia existencia moral" (Etchepare, 1910, p. 723). Así, con un médico centrándose sólo en 
una sexualidad hermafrodita desde lo psíquico, se muestra el camino de una mujer atravesada por una suma de exclusiones y abusos, una mujer inmigrante, que como objeto de la fascinante mirada clínica masculina, queda desdibujada en su singularidad mediante el recurso diagnóstico. Una mujer que pide salir del manicomio y no la dejan por su propia insignificancia.

Otras aristas de la sexualidad femenina se observa en el artículo del doctor Morales Pérez sobre la masturbación femenina realizada con las horquillas que sujetaban el pelo. En las líneas preliminares categoriza el tema con la siguiente frase: "Tuve ocasión de extraer una horquilla de las que usan las mujeres en la cabeza para sujetarse el pelo, que una soltera se había introducido en la vejiga en un momento de irreflexión gravísima, desviación de un perturbado instinto" (Morales Pérez, 1902, p. 428).

Suponemos que luego de tal relato, muchas mujeres preferían sufrir tremendos dolores y aún infecciones no tratadas, con tal de no avergonzarse frente a los médicos. Si las horquillas dañaban, pareciera que nunca el pene, en palabras de Alberto Chueco, médico del Hospital San Roque, que comenzaba otro artículo afirmando que el órgano viril masculino no era el responsable de las heridas producidas en la vagina de muchas pacientes. El autor, si bien afirmaba su distancia de la posición de los que sostenían que el pene tenía un rol pasivo en los traumatismos y que el factor activo era la impetuosidad de la mujer en el acto venéreo, agregaba que en los casos de violaciones y coito brutal, las heridas producidas por el miembro masculino se localizarían en el himen, grandes labios y periné mas no en las paredes y fondos de sacos vaginales. (Chueco, 1904). Con esto quedaba claro que la experiencia válida como traumática para la justicia y los hombres de ciencia era la de las mujeres vírgenes.

Una historia curiosa es relatada por el doctor Bernardo Etchepare. El síntoma de Ganser, como se lo denominaba, consistía en proferir las respuestas más absurdas a preguntas formuladas, acompañado de accidentes delirantes y alucinatorios sin que hubiera acuerdo entre los médicos o consenso acerca de la naturaleza de dicho síntoma. Se lo asociaba con la histeria, y propiamente con estados maníacos de abundancia de alucinaciones visuales. Lo que subrayaba el profesor de clínica psiquiátrica de la Facultad de Medicina, era que había que ser precavido a la hora de peritar, pues en histéricas acusadas de un acto criminal, las respuestas mal interpretadas habrían llevado a los médicos legistas al desgraciado diagnóstico de simulación (Etchepare, 1909). La histeria y su asequibilidad a la sugestión, sea ésta criminal o no, habían sido objeto de debate en otros centros científicos, como se observa en la escuela francesa con las teorías de Pierre Janet e Hippolyte Berheim (Fernández, López-Muñoz, Blasco \& Cortés, 2016). 


\section{Los casos judicializados}

A lo largo de los doce tomos consultados, sólo emergen unos pocos casos que mostraron un desarrollo de su etapa de instrucción y su sentencia judicial. Particularmente se presentan tres casos judicializados: uno por incapacidad civil y dos homicidios En el año II de los Archivos (1903) se reproduce un caso donde se dicta la incapacidad civil a causa de la locura de la interdicta, en el año IV (1905) se publica otro dossier en referencia a un homicidio aduciendo locura histérica, y en el año VI (1907) se incluye la sentencia de una homicida declarada absuelta en virtud de su honor ultrajado. En el mismo año se incorpora un proceso respecto del cumplimiento de los deberes matrimoniales.

\section{Locura histérica e incapacidad civil}

El caso es reportado en un informe presentado por un médico del Departamento Nacional de Higiene, Carlos Benites y un médico de Tribunales, Juan Acuña. Se trata de una mujer a quien debe practicarse el reconocimiento de las facultades mentales. Introducen el tema refiriendo que no tienen datos ciertos de los ascendientes o colaterales de la mujer, sino por referencias de personas a cuyas palabras dan crédito; es por ello que evalúan que habrían existido sujetos neuropáticos más o menos excéntricos en la línea vincular de la enferma. Prosiguen comentando la vida que ha llevado la misma, desde la infancia hasta su matrimonio, oportunidad en que comienzan los desvaríos. Las extravagancias de carácter se referían a la desatención e insensatez con las que la examinada trataba a su marido y familia. Tal extravagancia era configurada por lujos y coquetería. En contraste ofrecía la dejadez en su hogar, el cual confería al exclusivo cuidado de sirvientes sin dirección, (Benites \& Acuña, 1903). Era además descripta como fría, indiferente y egoísta con su familia. Con el correr del tiempo se volvió descuidada en su persona y se dedicó a la bebida:

Ella, que había sido de hábitos sobrios, bebía de una manera insaciable, tomaba vinos y sobre todo cerveza en grandes cantidades, tan pronto como conseguía eludir la vigilancia a que estaba sometida o escapaba a la calle para beber en la trastienda de los almacenes, sin el menor pudor ni consideración a su posición social (Benites \& Acuña, 1903, p. 211).

Al prohibírsele tales actos, estallaron en la examinada los síntomas que luego caracterizarían la verdadera insania según los autores. Tuvo ataques de máxima irritación ante las mínimas contrariedades, rompiendo vidrios y muebles y tratando de huir a como diera lugar, incluso llegando al intento de suicidio. 
Las pericias psíquicas describían que los encuentros eran tranquilos, y la mujer se conducía respondiendo a los exámenes de manera satisfactoria. La memoria, razonamiento y atención resultaban apropiados ante la indagatoria de los profesionales. A cuestiones de orden moral respondía de manera precisa. Ahora bien, refieren los facultativos que la reconocida por su falta de sentimientos hacia su familia, podría encuadrarse en locura moral, un estado mórbido caracterizado por exageración pasional con debilitamiento de la voluntad, más que por la perturbación de las facultades intelectuales. Por todo lo expuesto concluyeron que la señora padecía de enajenación mental bajo la forma de locura histérica con predominio de ideas delirantes, con pronóstico grave y que por tanto, se la inhabilitaba absolutamente para el ejercicio de sus derechos civiles.

Los juicios de insania e incapacidad civil consecuente fueron estandartes de una dominación médico-jurídica sobre las mujeres, que especialmente permiten entrever en el funcionamiento burocrático judicial la red de relaciones sociales y formas concretas que asumen las pericias psiquiátricas (Di Liscia, 2003). Los médicos de por entonces se encontraban en formación académica y vinculaban la capacitación con la pericia, aplicando teorías científicas imbuidas en valoraciones de género y clase. En la actuación de los médicos legistas se permea, por acción u omisión, la fundamentación o desestimación de la incapacidad civil de la mujer apoyándose en una valoración de género que dejaba al descubierto una noción clara del desempeño de una clase social. (Di Liscia, 2003). La insania de la mujer era una insania moral por no ajustarse a lo esperado para su condición de mujer decente, doméstica y centro afectivo del hogar (Castells, 2017). Desafectada, descuidada con sus hijos y labores, desesperada por la calle y el arreglo personal, ésta mujer de clase acomodada no podía más que ser una insana.

\section{Homicidio y falsa locura histérica. El histerismo y la responsabilidad penal}

Otra de las publicaciones judicializadas en los Archivos de Criminología data del año 1906. Se trata de una sentencia dictada por el juez de La Pampa, el Dr. Baltasar Beltrán (1906). Un homicidio había sido cometido por Fermina Díaz de Giménez, de 37 años de edad, viuda, residente en General Acha. En un terreno baldío, dentro de un pozo había sido hallado el cadáver de Gregorio González, más conocido como Patade-palo. Desde el comienzo se tuvo sospechas que la autora había sido Fermina, quien habitaba a unos quinientos metros del lugar donde fuere hallado el cuerpo sin vida. La causa de muerte según los médicos habían sido cinco grandes heridas producidas con hacha de monte en el cráneo y dos puñaladas en el pecho. Al comienzo la acusada había negado toda participación y conocimiento en el 
desventurado suceso. Mas la causa tomó un giro inesperado al ser detenido Casimiro Gómez. El mismo confesó que había ayudado a su suegra a transportar el cuerpo al pozo donde fue encontrado el difunto. Entonces Fermina confesó que había mantenido desde hacía tiempo una relación amorosa con el occiso. Ya cansada por el mal tratamiento que éste daba a sus hijas y habiéndolas aún amenazado de muerte, habría atentado contra la vida de su amante la última noche que estuvieron juntos. El factor detonante de dicha situación habría sido la exigencia de González de que tuvieran relaciones sexuales. Fermina se había negado y por ello el hombre persiguió con un cuchillo a Anita, una de las muchachas. Cuando estuvo acostado y ante el temor que efectivamente cumpliera con sus amenazas, la madre tomó el hacha y aplicó en la cabeza varios golpes hasta dejarle sin vida. Ayudada luego por sus dos hijas, transportó el cadáver con ayuda de su yerno a un zanjón cercano a la casa.

La acusación del Agente Fiscal tipificó al hecho como homicidio perpetrado con alevosía y ensañamiento y pidió condena penitenciaria por tiempo indeterminado. La defensa arguyó que el hecho había sido cometido bajo el estado de una crisis de histerismo, motivo por lo cual se solicitaba la absolución o al menos, disminución de la culpabilidad.

Los médicos legistas Fornes y Molas fueron nombrados a petición de la defensa, y junto con Oliver, médico del Tribunal, procedieron al peritaje. Llegaron a la conclusión de que la acusada padecía histeria hereditaria, sin poder precisar el grado de influencia de la patología en relación al delito cometido, ni tampoco la determinación del estado en que ésta se hallare al momento de la comisión del ilícito.

El juez adujo que los estados de histeria habían sido referidos por la misma peritada a los doctores intervinientes y no había constatación anterior de los mismos. Concluye que no es posible encuadrar a la susodicha dentro de las patologías histéricas descritas por Krafft-Ebing. En Fermina podían observarse signos característicos de la histeria en general y no podía establecerse que el hecho se hubiese cometido en un rapto de enajenación o sonambulismo. El motivo de tal conclusión sería que la mujer habría procedido por motivos lógicos como eran las amenazas de muerte. Sin embargo el juez supone que la verdadera causal era deshacerse del amante, para una vez libre, entregarse sin reatos a su nuevo querido, el italiano Licciardi, quien según constancias del proceso había comenzado a vincularse amorosamente con la acusada poco antes del asesinato. Los peritos refieren que la mujer llora cuando le hablan de su crimen o recuerda a sus hijas, lo que según el juez es signo de ausencia de la ceguera moral en las alienadas histéricas, capaces de delinquir sin motivo y de sentir remordimientos ni afección hacia los suyos. La conclusión del fundamento de la sentencia es que no está de acuerdo con la opinión del médico legista del Tribunal, el doctor Oliver, respecto del 
histerismo de la procesada. Un estado histérico de poca o aún mediana intensidad no habría comprometido la libertad moral de Fermina. El histerismo elevado a una alta potencia sí trae consigo la locura histérica, la cual era una enajenación verdadera comprendida en las causales eximentes según el Código Penal. Para Beltrán la acusada no era clínica ni jurídicamente una alienada y por ende no la alcanzaba el beneficio de la irresponsabilidad según el artículo 81 inciso primero del Código Penal de la época. Agrega el magistrado a la tipificación del homicidio la circunstancia agravante de la alevosía. Funda su convicción en el hecho que la víctima poseía una imposibilidad física de evitar la agresión, ya que carecía de una pierna que reemplazaba con un tosco aparato de madera origen de su apodo. Además el mismo se encontraba acostado, probablemente durmiendo.

La sentencia que condena a Fermina a doce años de prisión es apelada. Se realiza una nueva pericia respecto de la salud psicológica de la misma. El modo de ser de Fermina sería al momento del examen normal y concluye el informe que podría ser el mismo que existía al momento de cometer el delito. El Tribunal de Apelación confirma la sentencia dictada en Primera Instancia. Sin embargo, el caso es apelado nuevamente frente a la Corte Suprema de Justicia, máximo tribunal de revisión. La sentencia expresa que el delito y móviles objeto de la revisión del caso resultan plenamente comprobados. $Y$ como factor determinante se señala que los propósitos que determinaron a la procesada a cometer el delito revelan premeditación según lo que originariamente expresare la sentencia de Primera Instancia (Beltrán, 1907). Obviamente esta premeditación la deducían del nuevo romance de Fermina con el italiano.

El caso antes expuesto permite vislumbrar cómo los móviles que se suponen llevaron a la homicida a cometer el crimen, no son sino asentados en la fundamentación moral de la época. Resulta incómodo a los ojos del magistrado que la acusada tuviera ya otro amante y fuera éste el móvil para deshacerse del anterior. En tal circunstancia se opera con todo el rigor de la ley y se excluyen los eximentes de responsabilidad respecto de la mujer. Esta exclusión tiene su fundamento, no en las circunstancias del hecho sino en sospechas no probadas respecto del estado mental de la misma. En los casos de apelación los magistrados se habían limitado a comprobar el estado al momento de los posteriores procesos judiciales y no habían tenido en cuenta el momento del hecho en sí. Es claro el mensaje que con tres sentencias afirma una postura social: no es bien visto ser viuda y tener dos amantes, menos aún osar defender la vida de las hijas.

\section{Delincuencia pasional y honor ultrajado}


Una joven muchacha de veintidós años, soltera, de la provincia de Santa $\mathrm{Fe}$, había disparado un revólver hacia su prometido, el que luego había resultado muerto a raíz de la herida de arma de fuego. El mismo difunto, antes de morir le relató lo propio a un testigo aunque la versión respecto de los hechos difería. Pero el juez consideró que al ser el difunto parte interesada y carecer de consistencia el relato, debía ser desestimado. La acusada declara que se encontraba en casa de su cuñado cuando se cruza con su prometido y que lo increpa a raíz de querer abandonar éste el compromiso matrimonial que con ella tenía desde tiempo atrás. El prometido tenía intenciones de casarse con una prima y al ser interrogado confiesa que así lo hará. Luego la acusada refiere que al continuar la conversación, la víctima la abofetea. Entonces penetra en el escritorio de su cuñado, toma un revólver y con éste amenaza al hombre. El mismo se retira y ella vuelve a depositar el arma donde estaba, mas luego aparece enojado nuevamente por lo que ella vuelve a tomar el arma, le efectúa un disparo y lo hiere.

El juez considera que la causa primitiva de la catástrofe había sido que desde hacía tiempo la víctima había jurado a la acusada casarse con ella, y en prueba de fiel cumplimiento de dicho compromiso ella portaba un anillo con las iniciales de su novio. "Que luego ella, no dudando de su juramento y arrastrada por el cariño que a él profesaba llegó hasta entregarle su cuerpo y su honor, siendo este don el más preciado en la mujer" (Aragón, 1907, p. 730). Continúa el juez argumentando su sentencia en los dichos de la acusada, según los cuales el novio, sin darle ella motivos, se mostraba evasivo y evitaba su presencia. Al requerir el cumplimiento de la promesa de matrimonio éste se había negado y así le pega para luego desarrollarse el drama antes relatado.

Los argumentos a favor de la sentencia absolutoria radicaban en que la muchacha había tenido aproximación sexual con su prometido. Que ella en su corazón de novia engañada, actuó con justo furor frente al fierro candente de la vergüenza. Prosiguió diciendo que dicha catástrofe no fue buscada por la acusada sino por la víctima misma, un traidor que abandona su propósito matrimonial luego de deshonrarla. No se podía imputar por lo tanto criminalidad a la acción de la encausada. Ésta debía haber actuado en momento de desesperación, ante una fuerza moral irresistible que oprime la libertad, encontrándose tal situación recogida en el artículo 81 inciso $5^{\circ}$ del Código Penal. La mujer quedó en libertad declarándosela absuelta de culpa y cargo (Aragón, 1907).

\section{Sobre el cumplimiento de deberes matrimoniales}


El código civil redactado por Vélez Sársfield en 1869 contenía entre sus normas la regulación de los deberes matrimoniales, que básicamente se reducían a tres principales: fidelidad, cohabitación y asistencia (Brodsky, 2015). En particular, la cohabitación y asistencia por parte de la mujer se plasmaban en su letra original de la siguiente manera:

Art. 187. La mujer está obligada a habitar con el marido, dondequiera que éste fije su residencia. Si faltase a esta obligación, el marido puede pedir las medidas policiales necesarias, y tendrá derecho a negarle los alimentos. Los tribunales, con conocimiento de causa, pueden eximir a la mujer de esta obligación, cuando de su ejecución haya peligro de su vida.

En referencia a esta excepción planteada por el código en materia de convivencia se realiza un proceso publicado en los Archivos, según el cual la mujer, víctima de abuso sexual por parte de su cónyuge realiza una denuncia. En dicho caso interviene la justicia, la medicina legal, la policía y la Asistencia Pública. Y es curioso advertir cómo el título del artículo que plasma la sentencia reza: "Sobre el cumplimiento de los deberes matrimoniales", posicionándose el juez Quesada en la preeminencia del vínculo por sobre cualquier otro derecho que fuere vulnerado.

Se trata de una menor casada en el mes de julio que acude en agosto pidiendo se le nombre curador y se decrete su separación personal y depósito en casa de un cuñado en virtud de peligrar la vida de la misma por el abuso matrimonial que hacía su esposo, agravado por el abuso de la bebida. La esposa había abandonado el hogar a raíz de la violencia con la que su esposo accedía carnalmente. Según dichos de la denunciante, su marido hacía abuso por vía natural como por vía anal de manera harto violenta, y cuyos desmayos y sufrimientos fueron constatados por la Asistencia Pública. A raíz de ello, produjese una inflamación enorme con su consecuente estado de postración, durante el cual el hombre volvió a abusar con violencia por ambas vías. Excusa su accionar el marido al referir que obró de tal manera por el "exceso de cariño" pero que "su miembro no era desproporcionado" y tales serían inconvenientes derivados de los primeros días de matrimonio (Quesada, 1907). La intervención de la Asistencia Pública da cuenta de que los dolores sufridos por la mujer, seguidos de desmayos producto de accidentes histéricos. Los médicos de tribunales declaran que el miembro del marido es normal y que del examen de los órganos genitales de la mujer no se constatan violencias o traumatismos. Se hace referencia asimismo al artículo 210 del Código Civil de entonces que establecía que la mujer está obligada a habitar con su marido y que por tanto, la misma debía volver al hogar marital. Es de notar que los hechos denunciados fueron admitidos por el marido, pero se los consideraba legítimos respecto del vínculo matrimonial. Y es que por sobre todo, el 
caso muestra cuál era el bien legalmente protegido: el matrimonio y la necesaria sumisión de la esposa a raíz del vínculo y el efectivo cumplimiento de sus deberes derivados. La mujer fue considerada histérica.

\section{Reflexiones finales}

A los largo de los volúmenes de los Archivos de Criminología y Ciencias Afines se puede observar como en la caracterización de la mujer en conflicto con la ley aparece una conjunción de valoraciones consideradas científicas y jurídicas en la época con la mixtura de ponderaciones sociales. En efecto, la amalgama de discursos sobre el lugar de la mujer como buena madre y esposa con taxonomías de linaje científico conformaban una matriz explicativa única que los médicos y juristas, todos varones, empleaban para justificar sus diagnósticos y en ocasiones fundamentar sus sentencias judiciales. La mujer debía ser el centro de la domesticidad anclada en el espacio reproductivo del hogar. Debía habitar la moral y buenas costumbres siendo esposa o teniendo el proyecto de serlo. La mujer sustraída de la moralidad era la prostituta, un mal necesario para la sociedad. De ser tal el camino, la sociedad debía manejar el problema de la trata de blancas y la mujer caída ser plenamente identificada hasta el punto de llevar libreta con foto adosada. Además ella seguramente tendría inclinaciones mórbidas para serlo, herencias poco demostrables pero si eficaces en su poder rotulatorio. La homosexualidad femenina, denominada uranismo, sería otra costumbre a evitar en los internados de señoritas y una práctica antinatural junto a habitual compañero, el fetichismo. En el ámbito clínico se observaban locuras ancladas en la anatomía femenina y sus ciclos, como los estados puerperales y menstruales. Particularmente en el embarazo podían asumir la forma de trastorno o de psicosis bajo diversas formas y etiologías. Igual referencia a la toxicidad se explaya cuando se alude a la menstruación y la menopausia. La falta de caracterización de tales afecciones de síntomas y etiologías múltiples e indeterminadas, traía como consecuencia que frente a la ignorancia de las causas de una conducta no deseada, ésta fuera atribuida a tales patologías por ellos diagnosticadas. Entraba así dentro de este tipo de locuras cualquier circunstancia que no tuviera definición propia pero que estuviera encarnada en cuerpos femeninos. La ninfomanía era considerada una enfermedad que tenía condición hereditaria. Cualquier mujer que abusase del placer sexual padecía la misma. La condición de orfandad o abandono hacía que al desconocer el origen de la progenitora, se sospechara por tanto su anormalidad sin más. Consecuentemente las masturbaciones serán contempladas como desviaciones de perturbados instintos. Así, todo un espectro de conductas desviadas lo eran respecto de la norma de la mujer doméstica, mujeres sexualmente exultantes, con 
prácticas onanistas, ladronzuelas de vidrieras, lesbianas o prostitutas eran por extensión mujeres portadoras de estigmas de índole indefinida pero sin dudas patológicos y plausibles de intervención médico- jurídica.

En los casos tratados por la justicia penal la mujer doméstica operaba también como eje ordenador. La capacidad civil era abordada desde el seguimiento de las funciones de la mujer como ama de casa, esposa y madre. Si la misma no se adecuaba a las citadas tareas, el origen de tales comportamientos podía ser encontrado en la línea ascendente de la familia de la enferma. Sujetos neuropáticos entre sus parientes serían el origen de una patología heredada. La falta de adecuación al rol femenino importaba profundos desórdenes y perversiones de las demás facultades. La locura moral fue el diagnóstico con que se catalogó a la mujer referida, Y si bien no poseía ella sus facultades intelectuales alteradas, la inhabilitación absoluta fue reportada bajo el padecimiento de enajenación mental en su forma de locura histérica. Los homicidios fueron tratados de acuerdo a las circunstancias. Matar no era lo central de la cuestión, sino bajo qué hechos concomitantes. En el caso de una mujer homicida se la condena por haber ésta actuado con fines poco morales al tratar, según el juez, de deshacerse de un amante ya que tenía un nuevo amor en vista. No se toma como atenuante la circunstancia de que la procesada hubiere actuado en defensa de sus hijas y protegiendo la propia vida. En otro caso de homicidio, la acusada es exculpada ya que su crimen tendría justificación en la protección del honor ultrajado, bien supremo preciado en una mujer. La defensa del mismo habría habilitado a la perpetradora a quitar la vida a su prometido en vistas de incumplir el prometido matrimonio. Se podía matar por defender el pudor más no por defender la propia vida.

El último caso referido desestima el abuso sexual por parte del marido ante la denuncia de la mujer. El bien supremo a proteger era la cohabitación y el cumplimiento de los deberes matrimoniales estipulado en el código civil. Las reiteradas violaciones no lo eran tales por encontrarse la mujer bajo la egida del matrimonio. Los dos últimos casos nos hacen suponer que la misma mujer, el mismo varón y el mismo delito atravesarán diferentes destinos según aparezca o no el matrimonio como institución consumada.

Si tomamos a todos las caracterizaciones en su conjunto es fácil advertir que los textos presentados están escritos por varones portadores de discurso científico que toman como sujeto pasivo de análisis a mujeres doblemente pasivizadas en su condición de mujeres, víctimas y o/locas. Analizando los casos se puede concluir que no era la letra de la ley la que tipificaba qué tipo de accionar era punible. Eran las características de la mujer procesada, las circunstancias morales y las expectativas sociales que sobre ésta se tenían las que determinaban su culpabilidad o insania. La 
mujer delincuente o violentada no hallaba el amparo legalista en un código escrito, averiguar qué la llevó a delinquir o a ser víctima tampoco será importante. La adecuación al orden establecido será lo que determinará su categorización como mujer honesta, loca, anormal o delincuente. Los roles de género y de clase socialmente deseables para las mujeres de la época eran los que permeaban el aparato medico jurídico y verdaderamente marcaban los destinos de las mujeres.

\section{Referencias}

Albornoz Crespo, N. (2016). Itinerari alla periferia di Lombroso: Pietro Gori e la "Criminalogia moderna" in Argentina. Revista de historia del derecho, 52, 249252.

Aragón, R. (1907). Delincuencia pasional y honor ultrajado. Archivos de psiquiatría y criminología aplicadas a las ciencias afines, 6, 728-732.

Banerjee, S., Islam, M. \& Khatun, N. (2015). Theories of female criminality: a criminological analysis. International Journal of Criminology and Sociological Theory, 7, 1-8.

Barrancos, D. (2014). Sentidos, sentimientos y sensibilidades (1880-1930). Revista Latinoamericana de Estudios sobre Cuerpos, Emociones y Sociedad, 6(15),27-39.

Beltrán, B. (1906). Homicidio y falsa locura histérica: sentencia. Archivos de psiquiatría y criminología aplicadas a las ciencias afines, 5, 542-547.

Beltrán, B. (1907). Histerismo y responsabilidad penal: sentencia. Archivos de psiquiatría y criminología aplicadas a las ciencias afines, 6, 601-610.

Benites, C. \& Acuña, J. (1903). Locura histérica e incapacidad civil. Archivos de psiquiatría y criminología aplicadas a las ciencias afines, 2, 209-219.

Biernat, C. \& Simonetto, P. (2017). Imaginar a los enfermos: campañas privadas y públicas de profilaxis venérea en la Argentina de la primera mitad del siglo XX. Meridional: Revista Chilena de Estudios Latinoamericanos, 9, 113-143.

Brodsky, J. (2015). Los deberes personales de los cónyuges en el derecho Argentino y una breve glosa del artículo 431 del nuevo Código Civil y Comercial de la Nación. Lecciones y Ensayos, 94, 283-292.

Candiotti, M. (2002). Comentario a Eduardo A. Zimmermann: "los liberales reformistas: la cuestión social en Argentina 1890-1916". Delito y Sociedad, 1(17), 163-165.

Cantón, E. \& Ingenieros, J. (1903). Locura del embarazo. Archivos de psiquiatría y criminología aplicadas a las ciencias afines, 2, 548-556. 
Caponi, S. (2009). Para una genealogía de la anormalidad: la teoría de la degeneración de Morel. Scientiae Studia, 7(3), 425-445.

Castells, F. (2017). La temibilidad femenina en los discursos médico-legales argentinos (1902-1913). Revista de historia del derecho, 54, 1-10.

Chueco, A. (1904). Heridas de la vagina durante el coito. Archivos de psiquiatría y criminología aplicadas a las ciencias afines, 3, 197-203.

Ciancio, M. \& Gabriele, A. (2012). El archivo positivista como dispositivo visual-verbal: Fotografía, feminidad anómala y fabulación. Mora (Buenos Aires), 18(1), 29-44.

Dalla Corte Caballero, G. (1996a). Discusión sobre la influencia de la corriente criminológica positivista en el discurso penal argentino. Gimbernat: Revista Catalana d'Història de la Medicina i de la Ciència, 26, 157-169.

Dalla Corte Caballero, G. (1996b). Control de la procreación y generalización del Derecho Penal en la Argentina decimonónica: un estudio de caso. Arenal: Revista de historia de mujeres, 3(2), 279-302.

Di Corleto, J. (2010). Los crímenes de las mujeres en el positivismo: el caso de Carmen Guillot (Buenos Aires, 1914). Revista Jurídica de la Universidad de Palermo, 19-30.

Di Liscia, S. (2003). Mujeres, locura e incapacidad civil en Argentina, 1890-1920. Aljaba, Nueva Epoca, 8, 89-105.

Dovio, M. (2013). El caso de la 'mala vida', peligrosidad y prevención de conductas marginales en Revista de Criminología, Psiquiatría, Medicina Legal y Ciencias Afines, en Buenos Aires, 1914-1923. História, Ciências, Saúde-Manguinhos, 20, 1225-1252.

Etchepare, B. (1909). Histeria y síntoma de Ganser. Archivos de psiquiatría y criminología aplicadas a las ciencias afines, 8, 295-300.

Etchepare, B. (1910). Desequilibrio mental, morfinomanía e histeria. Archivos de psiquiatría y criminología aplicadas a las ciencias afines, 9, 717-723.

Fernández, F., López-Muñoz, F., Blasco, C. M.-M. \& Cortés, A. G. (2016). Apuntes para la comprensión del problema de la simulación en contextos diagnósticos. Un esbozo histórico. Revista de historia de la psicología, 37(4). 2-11.

Ingenieros, J. (1902). Valor de la psicopatología en la antropología criminal. Archivos de psiquiatría y criminología aplicadas a las ciencias afines, 1, 1-11.

Ingenieros, J. (1904). Los accidentes histéricos y las sugestiones terapéuticas. Buenos Aires: Menéndez. 
Ingenieros, J. (1905). Nueva clasificación de los delincuentes fundada en su psicopatología. Archivos de psiquiatría y criminología aplicadas a las ciencias afines, 4, 30-39.

Klappenbach, H. (2014). Acerca de la metodología de investigación en la historia de la psicología. Psykhe (Santiago), 23(1), 01-12.

Lancelotti, A. (1912). La criminalidad en Buenos Aires: 1885 a 1910 al margen de la estadística. Revista argentina de ciencias políticas, 4, 326-342.

Lombroso, C. (1899). La dismaternidad en la mujer delincuente. Criminalogía Moderna, 2(7), 201.

Mailhe, A. (2014). El archivo de Archivos: un latinoamericanismo eurocéntrico en la psiquiatría y la criminología de principios del siglo XX. Varia historia, 30(54), 655-678.

Mercante, V. (1905). Fetichismo y uranismo femenino en los internados educativos. Archivos de psiquiatría y criminología aplicadas a las ciencias afines, 4, 22-30.

Montero, B. (1903). Trata de blancas y moralidad pública. Archivos de psiquiatría y criminología aplicadas a las ciencias afines, 3, 210-223.

Morales Pérez, J. (1902). Horquillas en la masturbación femenina. Archivos de psiquiatría y criminología aplicadas a las ciencias afines, 1, 428-430.

Narvalaz, V. \& Miranda, M. (2009). La hipótesis de la degeneración en las historias clínicas del Hospicio de las Mercedes y la Colonia Dr. Cabred entre los años 1900 y 1930. Anuario de investigaciones, 16, 183-191.

Navarlaz, V. E. y Jardon, Magalí. (2010). Los diagnósticos y las historias clínicas de mujeres en los hospicios de Buenos Aires entre 1900-1930. Anuario de investigaciones, 17, 393-400.

Netri, F. (1902). El histerismo en la criminalidad. Archivos de psiquiatría y criminología aplicadas a las ciencias afines, 1, 143-161.

Oro, P. (1906). Consideraciones sobre psicosis puerperal. Archivos de psiquiatría y criminología aplicadas a las ciencias afines, 5, 582-605.

Ostrovsky, A. (2011) ¿Juntos o separados? La psicología de las niñas y los niños argentinos en la obra de Víctor Mercante (1870-1934). Revista de Historia de la Psicología, 32(4), 79-90.

Prins, E. (1903). Sobre la prostitución en Buenos Aires. Archivos de Criminología y Psiquiatría aplicadas a las Ciencias Afines, 2(12), 722-726

Quesada, E. (1907). Sobre el cumplimiento de los deberes matrimoniales. Archivos de psiquiatría y criminología aplicadas a las ciencias afines, 6, 219-222. 
Revilla, E. (1903). El ejercicio de la prostitución en Buenos Aires. Archivos de psiquiatría y criminología aplicadas a las ciencias afines, 2, 74-80.

Rossi, L. (2007). Publicaciones periódicas en Argentina: producción discursiva e institucionalización - referencias a la psicología. Anuario de investigaciones, 14, 157-164.

Salvatore, R. (2005). Sobre el surgimiento del estado médico legal en la Argentina (1890-1940). Estudios Sociales, 20(1), 81-114.

Sánchez, M. (2004). La mujer en la teoría criminológica. Revista de Estudios de Género La ventana, 20, 240-246.

Sicardi, F. (1903). La vida del delito y de la prostitución. Archivos de psiquiatría y criminología aplicadas a las ciencias afines, 2, 11-21.

Sozzo, M. (2016). "Los exóticos del crimen" Inmigración, delito y criminología positivista en la Argentina (1887-1914). Avances de Investigación, 20(32), 1951.

Suriano, J. (Org.). (2004). La cuestión social en Argentina, 1870-1943. Buenos Aires: La Colmena.

Talak, A. \& Miranda, M. (2010). Progreso, degeneración y darwinismo en la primera psicología argentina, 1900-1920. En G. Vallejo \& M. Miranda (Org.s). Derivas de Darwin: cultura y política en clave biológica (pp. 299-320). Buenos Aires: Siglo XXI.

Tkocz, I. \& Holguín, J. A. T. (2018). Historia y sus métodos: el problema de la metodología en la investigación histórica. Debates por la Historia, 6(1), 117-139.

Topolsky, J. (1985). La naturaleza y los instrumentos de la narración histórica. En J. Topolsky. Metodologia de la historia (3a ed.; pp. 465-472). Madrid: Cátedra.

Trochón, Y. (2006). Trata de blancas en el Atlántico Sur: Argentina, Brasil y Uruguay (1880-1932). Buenos Aires: Taurus.

Vezzetti, H. (1983). La locura en la Argentina. Buenos Aires: Folios.

Zimmermann, E. (1992). Los intelectuales, las ciencias sociales y el reformismo liberal: Argentina, 1890-1916. Desarrollo económico, 31(124) ,545-564.

\section{Nota sobre las autoras}

Ana Elisa Ostrovsky es Profesora Tirular de la catedra Historia Social de la Psicologia. Universidad Nacional de Mar del Plata. Argentina. Investigadora Adjunta CONICET. E-mail: anaelios@gmail.com 
Viviana Miriam Alfonso es Licenciada en Psicología. Adscripta a la catedra Historia Social de la Psicologia E-mail: vi-alfonso@hotmail.com

Data de recebimento: $31 / 03 / 2019$

Data de aceite: 16/09/2019 